\title{
Endometrial Cancer: What Is New in Adjuvant and Molecularly Targeted Therapy?
}

\begin{abstract}
Flora Zagouri, ${ }^{1}$ George Bozas, ${ }^{1,2}$ Eftichia Kafantari, ${ }^{1}$ Marinos Tsiatas, ${ }^{1}$ Nikitas Nikitas, ${ }^{1}$ Meletios-A. Dimopoulos, ${ }^{1}$ and Christos A. Papadimitriou ${ }^{1}$
\end{abstract}

\author{
${ }^{1}$ Department of Clinical Therapeutics, "Alexandra" Hospital, School of Medicine, University of Athens, Athens, Greece \\ ${ }^{2}$ Oncology Centre, Castle Hill Hospital, Hull and East Yorkshire NHS Trust, Cottingham, UK
}

Correspondence should be addressed to Christos A. Papadimitriou, chr_papadim@yahoo.gr

Received 27 September 2009; Accepted 8 December 2009

Academic Editor: Paul J. Hoskins

Copyright ( 2010 Flora Zagouri et al. This is an open access article distributed under the Creative Commons Attribution License, which permits unrestricted use, distribution, and reproduction in any medium, provided the original work is properly cited.

\begin{abstract}
Endometrial cancer is the most common gynaecological cancer in western countries. Radiotherapy remains the mainstay of postoperative management, but accumulating data show that adjuvant chemotherapy may display promising results after staging surgery. The prognosis of patients with metastatic disease remains disappointing with only one-year survival. Progestins represent an effective option, especially for those patients with low-grade estrogen and/or progesterone receptor positive disease. Chemotherapy using the combination of paclitaxel, doxorubicin, and cisplatin is beneficial for patients with advanced or metastatic disease after staging surgery and potentially for patients with early-stage disease and high-risk factors. Toxicity is a point in question; however, the combination of paclitaxel with carboplatin may diminish these concerns. In women with multiple medical comorbidities, single-agent chemotherapy may be better tolerated with acceptable results. Our increased knowledge of the molecular aspects of endometrial cancer biology has paved the way for clinical research to develop novel targeted antineoplastic agents (everolimus, temsirolimus, gefitinib, erlotinib, cetuximab, trastuzumab, bevacizumab, sorafenib) as more effective and less toxic options. Continued investigation into the molecular pathways of endometrial cancer development and progression will increase our knowledge of this disease leading to the discovery of novel, superior agents.
\end{abstract}

\section{Introduction}

Endometrial cancer is the most prevalent gynecological cancer in the Western World representing the third commonest cancer affecting women. By contrast, the incidence in the non-Western World is approximately tenfold lower [1]. The excellent prognosis of early-stage endometrial cancer renders it one of the most curable gynecological malignancies. Radiotherapy remains the mainstay of postoperative management, but accumulating data show that adjuvant chemotherapy may display promising results after staging surgery. The term staging surgery implies to hysterectomy, bilateral salpingoophorectomy, and pelvic and para-aortic node dissection with or without omentectomy. Unfortunately, the prognosis of patients with metastatic disease remains disappointing with only one-year survival commonly reported despite treatment efforts [2].
Systemic interventions play a key role in the treatment of advanced/metastatic and relapsed endometrial cancer. Progestins remain an effective option, especially for those patients with low-grade estrogen and/or progesterone receptor positive disease, some of whom achieve prolonged survival [3-14]. Platinum compounds, anthracyclines, and more recently taxanes have been developed in combination regimens, achieving response rates exceeding 50\% and resulting in more than one-year survival in randomized trials $[2,15-40]$. Today, the combination of doxorubicin $45 \mathrm{mg} / \mathrm{m}^{2}$, cisplatin $50 \mathrm{mg} / \mathrm{m}^{2}$, and paclitaxel $160 \mathrm{mg} / \mathrm{m}^{2}$ (TAP) [29] is considered the most effective chemotherapy regimen for advanced or recurrent endometrial cancer. A large GOG trial which is currently evaluating TAP against paclitaxel and carboplatin may at last provide conclusive data on the comparative efficacy of the less toxic nonanthracycline combination [2]. It is worth mentioning that the GOG 
209 trial has closed to accrual, although results are not yet available.

Adjuvant chemotherapy using the same agents is beneficial for patients with advanced disease after staging surgery and potentially for patients with early-stage disease and high-risk factors, such as high-grade or nonendometrioid histology. Their combination with radiotherapy is still under debate. Toxicity is a point in question for endometrial cancer patients treated with chemotherapy, given their often advanced age and multiple comorbidities. Hematologic toxicity, cardiac toxicity, and neurotoxicity probably present more cause for concern, as they can increase the risk of treatment-related death or long-term disabilities. The development of less toxic regimens such as the combination of paclitaxel with carboplatin may diminish these concerns.

Our increased knowledge of the molecular aspects of endometrial cancer biology has paved the way for clinical research to develop novel targeted antineoplastic agents as more effective and less toxic options. This review article aims to present the gathering evidence of current adjuvant systemic treatment of endometrial cancer in an attempt to direct ongoing clinical research.

\section{Adjuvant Chemotherapy}

Radiotherapy (vaginal brachytherapy and/or pelvic irradiation) remains the mainstay of postoperative management, decreasing the rate of pelvic recurrences. Moreover, it is the preferred sole method of treatment for patients with highrisk and may be intermediate-risk early-stage disease [4143]. Additionally, it is worth mentioning that trials in earlystage disease have shown decreased locoregional recurrence but no improvement in survival with radiotherapy. The use of adjuvant systemic treatment in endometrial cancer is an individualised decision based on the assessment of prognostic factors which increase the potential for relapse and distant metastasis such as stage, age $>70$ years, and histological characteristics (grade, serous or clear cell type, lymphovascular space invasion) $[42,44]$. The anticipated benefits and risks for toxicity are also taken into the equation. Grade 3 endometrioid tumours, as well as the serous and clear cell variants, display a more aggressive behaviour than grades 1 and 2 endometrioid cancers. These high-risk types are commonly diagnosed as advanced or metastatic disease but early-stage cancers can also result in similarly unfavourable outcomes [45]. Surgical staging procedures also play a significant role, since a recurrence risk for a proportion of patients with ostensible stage I disease and high-risk histology may be underestimated $[45,46]$.

Although current evidence does not support the use of progestins in the adjuvant treatment of endometrial cancer $[47,48]$, chemotherapy may prove beneficial in patients with high-risk features. Three randomised trials comparing chemotherapy with radiotherapy for high- and intermediaterisk endometrial cancer have produced somewhat equivocal but important results (Table 1).

Randall et al. reported the results of the GOG protocol 122 which randomized 396 women with stage III
GOG 122

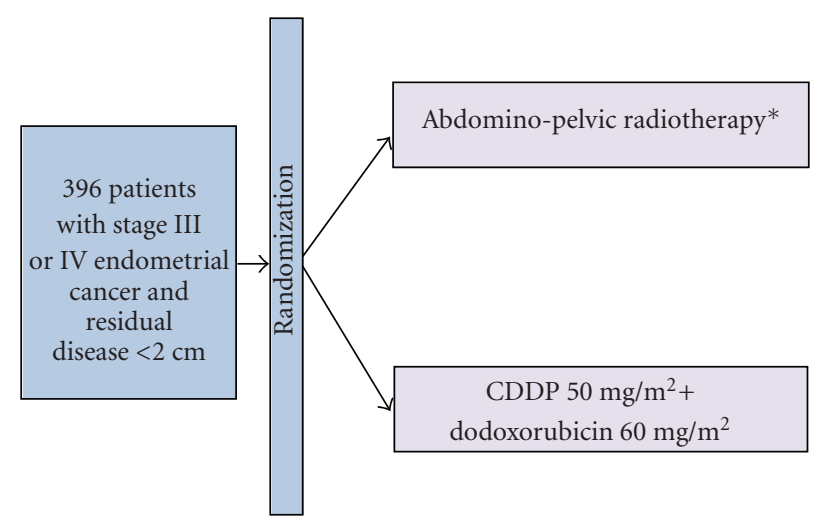

Figure 1: Postoperative whole abdominal radiotherapy versus combination doxorubicin-cisplatin chemotherapy in advanced endometrial carcinoma. *30-Gy in fractions with a 15-Gy boost.

and optimally debulked stage IV endometrial cancer to postoperatively receive either whole abdominal irradiation (WAI) or chemotherapy with cisplatin and doxorubicin (Figure 1). This study favoured chemotherapy with a hazard ratio for progression of 0.71 and 0.68 for death, and five-year survival rate of $55 \%$ versus $42 \%$, respectively [49]. Another trial included 345 intermediate- and high-risk patients (stage IC grade 3 , stage II grade 3 with $>50 \%$ myometrial invasion, and stage III) who were randomized to receive adjuvant chemotherapy with cisplatin, doxorubicin, and cyclosphosphamide (CAP) or external beam radiotherapy (pelvic and paraortic). Similar results in overall and diseasefree survival were reported for both arms. The authors noted that radiotherapy did improve local relapse rates, while chemotherapy improved the risk for distance metastases [50]. The latest published study comparing chemotherapy with radiotherapy randomized 385 patients with $>50 \%$ myometrial invasion, $61 \%$ of whom had stage I disease, to receive either CAP or external beam pelvic radiotherapy. Although the 5-year OS and PFS rates were similar in both arms, a significant improvement of PFS $(\mathrm{HR}=0.44)$ and OS $(\mathrm{HR}=0.24)$ was observed with chemotherapy in a subgroup comprising patients with stage IC and $>70$ years old, stage IC and grade 3 endometrioid tumors, stage II, and stage IIIA (positive cytology) [51]. Interestingly, no significant increase in adverse effects was observed in the CAP group versus the radiotherapy group.

Single modality adjuvant treatment with chemotherapy entails a high risk of local relapse. Indeed, 36\% of the initial recurrences were limited to the pelvis in the GOG 122 study [49]. This presents a strong argument for the implementation of combined modality treatments. Nevertheless, salvage external beam radiotherapy in previously nonirradiated patients with locoregional recurrence has resulted in five-year local control rate of $54 \%$, disease specific survival of $51 \%$, and overall survival of $44 \%$ [42]. Consequently, radiotherapy could be considered in later stages of management rather than postoperatively with less risk for combined toxicities. In the RTOG 9708 study, 46 patients 
TABLE 1: Trials on adjuvant treatment for endometrial cancer.

\begin{tabular}{|c|c|c|c|c|c|c|}
\hline Author(s) & $\begin{array}{l}\text { Setting } \\
\text { (Stage) }\end{array}$ & $\begin{array}{c}\text { Pts } \\
\text { (No.) }\end{array}$ & Treatment arms & $\begin{array}{c}\text { 5-year PFS } \\
(\%) \\
\end{array}$ & $\begin{array}{c}\text { 5-year OS } \\
(\%) \\
\end{array}$ & Comments \\
\hline \multirow{2}{*}{ Randall et al. [49] } & III-IV & \multirow{2}{*}{396} & $\mathrm{WAI}^{3}$ & 38 & 42 & \multirow{2}{*}{$\begin{array}{l}\text { Treatment related deaths AP: } 8 \\
(4 \%), \text { WAI: } 5(2 \%)\end{array}$} \\
\hline & (optimally debulked) & & $\mathrm{AP}^{4}$ & 50 & 55 & \\
\hline \multirow{3}{*}{ Maggi et al. [50] } & \multirow{3}{*}{ ICG3-III } & \multirow{3}{*}{345} & External beam & 63 & 69 & \\
\hline & & & $\mathrm{XRT}^{5}$ & & & \\
\hline & & & $\mathrm{CAP}^{6}$ & 63 & 66 & \multirow{5}{*}{$\begin{array}{l}\text { Superiority of CAP in } \\
\text { high/intermediate risk } \\
\text { (stICG3-IIIA) patients }\end{array}$} \\
\hline \multirow{2}{*}{ Susumu et al. [52] } & \multirow{2}{*}{$\begin{array}{l}>50 \% \text { myometrial } \\
\text { invasion }\end{array}$} & \multirow{2}{*}{385} & Pelvic XRT & 83.5 & 85.3 & \\
\hline & & & CAP & 81.8 & 86.7 & \\
\hline \multirow{2}{*}{ Hogberg et al. [53] } & \multirow{2}{*}{$\begin{array}{l}\text { IC-IIIC } \\
\text { (confined to pelvis) }\end{array}$} & \multirow{2}{*}{367} & Relvic XRT +/- BT $^{7}$ & 75 & $\mathrm{NR}^{8}$ & \\
\hline & & & Pelvic RT +/- BT + $\mathrm{Cx}^{9}$ & 82 & NR & \\
\hline \multirow{2}{*}{ Kuoppala et al. [51] } & \multirow{2}{*}{ IAG3-IIIA } & \multirow{2}{*}{156} & Pelvic XRT & $18+$ months & 84.7 & $\begin{array}{l}\text { Intestinal complications } \\
\text { demanding surgery }\end{array}$ \\
\hline & & & Pelvic XRT + CEP ${ }^{10}$ & $25+$ months & 82.1 & $\begin{array}{l}\text { XRT: } 2(2.7 \%) \text {, Pelvic XRT + } \\
\text { CEP: } 8(9.5 \%)\end{array}$ \\
\hline
\end{tabular}

${ }^{1} \mathrm{PFS}$, progression-free survival; ${ }^{2} \mathrm{OS}$, overall survival; ${ }^{3} \mathrm{WAI}$, whole abdominal irradiation; ${ }^{4} \mathrm{AP}$, doxorubicin and cisplatin; ${ }^{5} \mathrm{XRT}$, irradiation; ${ }^{6} \mathrm{CAP}$, cyclophosphamide, doxorubicin and cisplatin; ${ }^{7} \mathrm{BT}$, vaginal brachytherapy; ${ }^{8} \mathrm{NR}$, not reported; ${ }^{9} \mathrm{Cx}$, chemotherapy with AP or paclitaxel, epirubicin and carboplatin or paclitaxel and carboplatin; ${ }^{10} \mathrm{CEP}$, cyclophosphamide, epirubicin and cisplatin.

with endometrial cancer confined to the pelvis (stage I to IIIC) displaying adverse histological prognostic factors were treated with chemo-radiotherapy followed by chemotherapy with cisplatin and paclitaxel. The 5-year DFS and OS rates for stage III patients were $72 \%$ and $77 \%$, respectively, and no relapses in stage I or II patients were recorded. However, a grade 4 long-term toxicity was reported in $4 \%$ of patients [54]. The NSGO-EC-9501/EORTC 55991 study randomized 372 patients with high-risk endometrial cancer (grade 3, deep myometrial invasion, DNA nondiploidy, serous, clear-cell, or anaplastic histology) of surgical stages I to IIIC and without paraortic lymph node involvement to receive either external beam irradiation with or without vaginal brachytherapy, or radiotherapy plus platinum-based chemotherapy. The results favoured the combined modality treatment with an HR of 0.58 for PFS [53]. Nevertheless, another recently published study of sequential chemoradiotherapy (cyclophosphamide, cisplatin, epirubicin) versus radiotherapy alone in 157 patients, with stage IA/B, grade 3 and stages IC to IIIA of any grade, failed to show a statistically significant improvement in survival outcomes. Furthermore, chemotherapy seemed to increase intestinal toxicity requiring surgery [51].

It has become clear that questions surrounding adjuvant chemotherapy in endometrial cancer and its optimal application are far from being settled and hence form an active field of clinical research. The use of newer agents, such as paclitaxel, appears promising. Its combination with carboplatin has shown favourable efficacy and toxicity as adjuvant treatment of endometrial cancer [55] and may prove to be a valid and less toxic option to anthracyclineplatinum combinations. GOG protocol 184 (Figure 2) deals with advanced stage patients randomized after surgery with optimal debulking (diameter $\leq 2 \mathrm{~cm}$ ) and tumor-directed

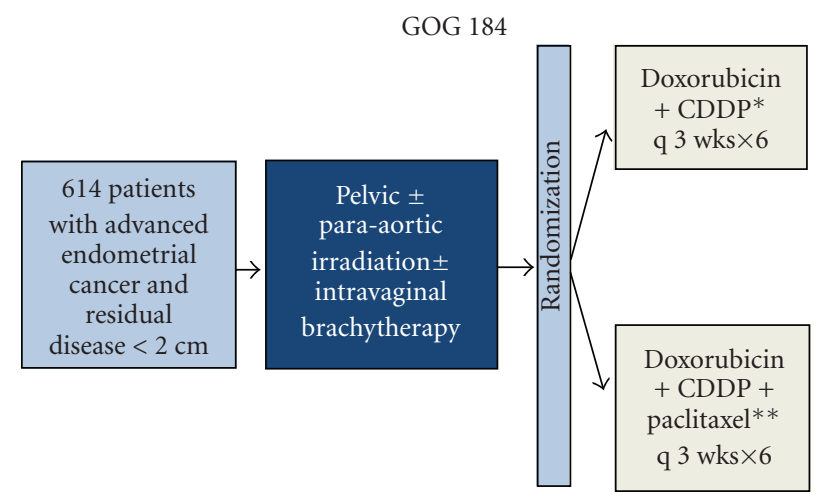

(a)

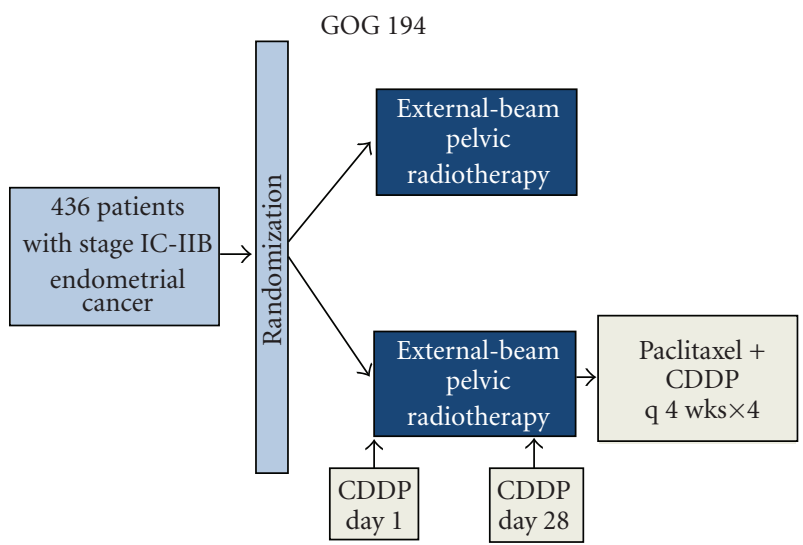

(b)

FIGURE 2: Recent randomized GOG trials of postoperative radiotherapy and/or combination chemotherapy in endometrial cancer. ${ }^{*}$ Both arms received G-CSF. ${ }^{* *}$ Paclitaxel was administrated on day 2 . 


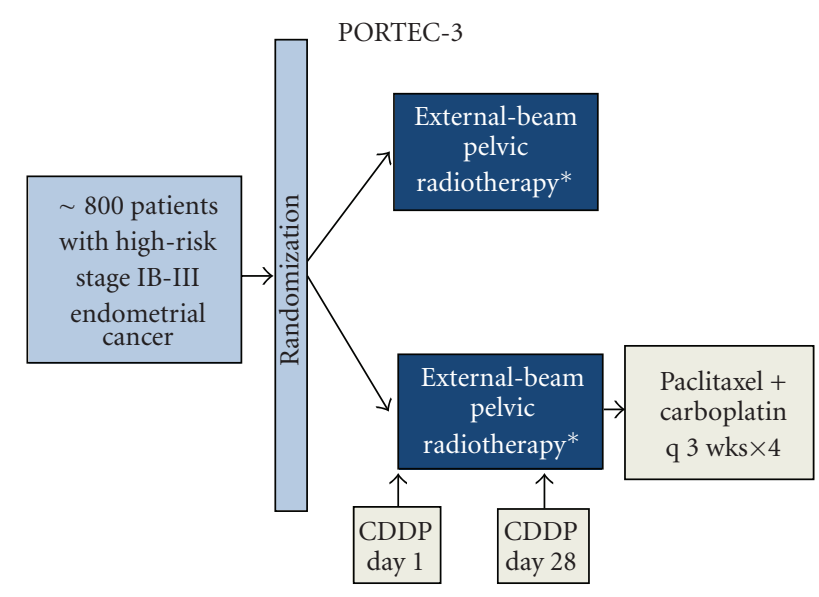

Figure 3: Chemotherapy and radiation therapy compared with radiation therapy alone in treating patients with high-risk stage I, stage II, or stage III endometrial cancer. ${ }^{*}$ Patients with cervical involvement undergo vaginal brachytherapy.

radiation to cisplatin and doxorubicin with or without paclitaxel. There was no statistically significant improvement in recurrence free survival between the two regimens. Overall, the addition of paclitaxel had little impact on recurrence free survival and was associated with increased morbidity. Of note, subset analysis revealed a 50\% reduction in the risk of recurrence or death for patients with gross residual disease in the triplet arm when compared to the doublet one [56]. The advantages of identifying early-stage patients who may benefit from adjuvant chemotherapy are the subject of GOG 194 (Figure 2) and PORTEC-3 (Figure 3) trials, evaluating the addition of paclitaxel and either cisplatin or carboplatin to adjuvant radiotherapy. Notably, the aggressive nature of serous and clear cell tumours and a wealth of data from nonrandomized studies [30-41, 54, 57-67] have led many institutions to standardize adjuvant chemotherapy for all early-stage patients with such histology. However, the small volume of patients belonging to these subgroups ( $2 \%-4 \%$ of stage I endometrial cancer) hampers the design of a phase III study to further clarify the merits of this approach.

\section{Toxicity of Systemic Chemotherapy for Endometrial Cancer and Patient Selection}

Patients with endometrial cancer often present cause for concern due to toxicity, given that they are often of advanced age, with poor performance status and multiple comorbidities. The significance of age and coexisting medical conditions in clinical decision-making can be extrapolated from the observation that $40 \%$ of deaths in patients participating in clinical trials are attributed to conditions other than endometrial cancer [41]. Whilst it is true that more intensive combination regimens achieved greater efficacy in advanced or recurrent endometrial cancer, toxicity was unfortunately increased. Even among selected populations of phase II or III trials, treatment-related deaths are not uncommon despite the use of G-CSF $[25-27,29,35]$. A meta-analysis of pooled toxicity data from five randomized trials $[17-19,29,68]$ comparing less intensive with more intensive chemotherapy showed that treatment intensification resulted in higher rates of severe (grades 3 and 4) nausea and vomiting, gastrointestinal toxicity, thrombocytopenia, infection, renal toxicity, and neurotoxicity with odds ratios of $2.73,2.48,4.44,4.36,3.55$, and 5.81 , respectively [15].

Toxicity far outweighs any concerns in the adjuvant setting. In the phase III trial comparing WAI with AP chemotherapy for stage III/IV endometrial cancer after staging surgery, 13 treatment-related deaths were reported among 396 randomized patients, most of which involved the chemotherapy arm. Severe hematologic toxicity was documented in $88 \%$ of patients on AP as opposed to $14 \%$ of those on WAI arm [49]. Furthermore, 17\% of patients receiving AP discontinued treatment due to toxicity, compared to only $3 \%$ treated with WAI. Maggi et al. [50] reported a rate of $35 \%$ for grades 3 and 4 neutropenia in stage IC-III patients receiving adjuvant CAP as opposed to a $16 \%$ rate of severe gastrointestinal toxicity in patients treated with radiotherapy [50]. Gastrointestinal toxicity may be more frequently observed in patients receiving both radiotherapy and chemotherapy, as reported by Kuoppala et al. [51], where the addition of the cyclophosphamide, epirubicin, and cisplatin (CEP) regimen to pelvic irradiation increased the rate of gastrointestinal complications requiring surgery from $2.7 \%$ to $9.5 \%$.

Since previous pelvic irradiation depletes the hematopoietic stem cell pool and increases the potential for severe hematologic toxicity, such patients have habitually received lower doses of chemotherapy in phase III trials [17, 29, 35]. Albeit G-CSF support may improve the tolerability of doublet and triplet regimens, grade 4 neutropenia remains notably frequent at over $35 \%[29,35]$.

Elderly patients with predisposing factors or preexisting cardiac disease about to be treated with anthracycline based chemotherapy are a source of concern for cardiotoxicity. Patients enrolled in studies are routinely screened for left ventricular function defects and those with preexisting dysfunction or active coronary heart disease are typically excluded $[17-19,23,29]$. Finally, patients with longstanding diabetes mellitus may be more prone to neurotoxicity, a debilitating condition commonly associated with combinations including cisplatin and/or paclitaxel $[20-22,26]$.

The use of prophylactic G-CSF, as well as the use of single-agent chemotherapy or less toxic regimens, such as the combination of carboplatin with paclitaxel or carboplatin with liposomal doxorubicin, is reasonable options to be considered for improved tolerability.

Overall, research data should be interpreted with caution. Populations treated in studies are very likely to differ from the average population encountered in common clinical practice; quality of life factors must be considered in the individualization of management decisions. 


\section{Targeted Therapy for Endometrial Cancer}

4.1. Genetic Alterations in Endometrial Cancer. Nowadays, we have a better understanding of molecular characteristics of endometrial cancer which seem to concur with previously established clinical and histological disease types (Table 2) [69-79]. The importance of angiogenesis has been recognised in regard to the natural history of endometrial cancer and presents potential clinical and therapeutic implications. Tumor suppressor protein PTEN (phosphatase and tensin homolog deleted on chromosome ten), a lipidprotein phosphatase key to the regulation of normal cell function, has been reported to be altered in up to $83 \%$ of endometrioid carcinomas $[76,80,81]$. PTEN inactivation is most commonly caused by mutations in both alleles resulting in the complete loss of function (reviewed in $[76,80])$. It principally targets and dephosphorylates 3, 4, 5-trisphosphoinositides resulting in the inhibition of the phosphatidylinositol-3 kinase (PI3K) pathway [82]. Total lack or impairment of PTEN protein from cancer cells causes hyperactivation of the PI3K pathway, leading to uncontrolled function of several kinases, including the serine/threonine kinase mTOR (mammalian target of rapamycin) (reviewed in [80]). PI3KCA mutation is seen in $36 \%$ of endometrioid endometrial cancers and is most common in tumors that also bear the PTEN mutation [83]. Additionally, the upregulation of proapoptotic mechanisms involving AKTdependent mechanisms is mediated through PTEN, as is the downregulation of antiapoptotic mechanisms through Bcl-2 [84]. Since the protein phosphatase activity of PTEN is involved in the inhibition of focal adhesion formation, cell spread, and migration, as well as the inhibition of growth factor-stimulated MAPK signaling, a failed or altered PTEN expression can result in aberrant cell growth and apoptotic escape (reviewed in [76]).

Microsatellite instability (MSI) [85], specific mutations of K-ras [86], and $\beta$-catenin genes [87] are other genetic alterations in endometrioid endometrial cancer. Microsatellites are short segments of repetitive DNA bases scattered throughout the genome predominantly found in noncoding DNA. MSI, reported in $20 \%$ of sporadic endometrioid endometrial cancers, is caused by inactivation of any number of intranuclear proteins comprising the mismatch repair system, leading to an accumulation of structural changes in coding and noncoding repetitive elements of many genes [85]. Higher rates of mutations in the PTEN gene have been described in tumors displaying MSI as opposed to those that do not, suggesting that PTEN could be a target for mutations in a deficient DNA repair setting [88].

$\beta$-catenin, a component of the E-cadherin unit of proteins, plays an important role to cell differentiation, maintenance of normal tissue architecture, and to signal transduction. It also acts as a downstream transcriptional activator in the Wnt signal transduction pathway. These mutations result in stabilization of protein that resists degradation through the ubiquitin-proteasome pathway, leading to cytoplasmic and nuclear accumulation and constitutive target gene activity (reviewed in $[76,89,90])$.
Mutations in p53 are present in about $90 \%$ of tumors and constitute the most common genetic alterations in type 2 serous carcinomas [86]. After DNA damage, nuclear p53 accumulates and causes cell cycle arrest by inhibiting cyclin$\mathrm{D} 1$ phosphorylation of the $\mathrm{Rb}$ gene, thereby promoting apoptosis [89]. Mutated p53 results in a nonfunctional protein that accumulates in the cell and acts as a double negative inhibitor of the wild-type p53, leading to propagation of aberrant cells. It has been suggested that mutation in one allele occurs during early development of serous carcinoma, and loss of the second normal allele occurs late in the progression to carcinoma. Other frequent genetic alterations in type 2 endometrial cancers include inactivation of p16 and overexpression of HER-2/neu [89]. Inactivation of p16 tumor suppressor gene, that encodes for a cell cycle regulatory protein, leads to uncontrolled cell growth and has been identified in $45 \%$ of serous carcinomas and some clear cell cancers (reviewed in [76]). HER-2/neu is an oncogene that codes for a transmembrane receptor tyrosine kinase involved in cell signaling. HER-2 overexpression and gene amplification have been found in $45 \%$ and $70 \%$ of serous carcinomas, respectively [91].

\subsection{Molecularly Targeted Therapy}

4.2.1. mTOR Inhibitors. The activation of the PI3K/AKT/ mTOR signalling pathway triggered by the loss of function of PTEN gene suggests a therapeutic role for the mammalian target of rapamycin (mTOR) inhibition. Chemotherapynaïve endometrial cancer patients treated with temsirolimus, an mTOR inhibitor, achieved a preliminary response rate of $26 \%$ according to the National Cancer Institute of Canada; this result was not correlated to PTEN status as evaluated by immunohistochemistry [92]. Preliminary studies of other mTOR inhibitors, everolimus and AP2357, have shown clinical responses mainly in the form of stable disease ( 8 of 15 and 7 of 19 women, resp.) [93-95]. A phase II trial of temsirolimus in heavily pretreated patients with endometrial cancer, recently completed by the NCIC, reported a $7 \%$ partial response rate and a $44 \%$ stable disease rate [96]. It should be noted that the trials of everolimus and AP2357 were both in pretreated patients. Combinations of mTOR inhibitors with hormonal therapy, chemotherapy, or other targeted therapies such as epidermal growth factor receptor (EGFR) inhibitors and antiangiogenic agents have shown such promise, in the preclinical setting, that numerous trials are currently underway to develop and test such combinations; temsirolimus is being tested with topotecan, bevacizumab and progestin therapy (reviewed in [80]). It has been shown that exposure of endometrial cancer cell lines to an mTOR inhibitor increases progesterone mRNA expression and inhibits ER mRNA expression (reviewed in [80], [97]).

\subsubsection{Human Epidermal Growth Factor Receptor (EGFR) or HER Family Inhibition}

EGFR Inhibitors. EGFR is commonly expressed in normal endometrium, but its overexpression in endometrial cancer 
TABLE 2: Types of endometrial cancer according to the Bokhman model and correlations with clinicopathological and molecular characteristics.

\begin{tabular}{|c|c|c|}
\hline Characteristics & Type I tumors & Type II tumors \\
\hline \multicolumn{3}{|l|}{ Clinicopathological } \\
\hline Incidence & $\sim 80 \%$ & $\sim 20 \%$ \\
\hline Age at initial diagnosis & Pre/peri-menopausal & Postmenopausal \\
\hline Histology & Endometrioid & $\begin{array}{l}\text { Non-endometrioid } \\
\text { (predominantly serous and } \\
\text { clear cell) }\end{array}$ \\
\hline Grade & Usually low & Usually high \\
\hline Premalignant phase & Atypical hyperplasia & $\begin{array}{l}\text { Glandular dysplasia (for } \\
\text { serous tumours) }\end{array}$ \\
\hline Predisposing factors & $\begin{array}{l}\text { Obesity, prolonged estrogen } \\
\text { exposure }\end{array}$ & \\
\hline ER, PgR & $>90 \%$ & $0-31 \%$ \\
\hline \multicolumn{3}{|l|}{ Molecular } \\
\hline HER-2/neu (overexpression) & $3 \%$ & $18 \%$ \\
\hline EGFR expression & $46 \%$ & $34 \%$ \\
\hline P53 mutations & $5-10 \%$ & $80-90 \%$ \\
\hline Ploidy & $67 \%$ diploid & $45 \%$ diploid \\
\hline PTEN (loss of function through deletion or mutation) & $50-80 \%$ & $10-11 \%$ \\
\hline P16 inactivation & $10 \%$ & $40 \%$ \\
\hline K-ras (mutational activation) & $13-26 \%$ & $0-10 \%$ \\
\hline E-cadherin (reduced or non expression) & $10-20 \%$ & $62-87 \%$ \\
\hline$\beta$-catenin CTNNB1 (gain of function mutation) & $25-38 \%$ & Rare \\
\hline
\end{tabular}

is associated with advanced stage and poor prognosis [98103]. Antagonists to EGFR include small molecule tyrosine kinase inhibitors (gefitinib, erlotinib, and lapatinib) and the anti-EGFR monoclonal antibody cetuximab. The use of erlotinib in women with recurrent and metastatic endometrial cancer was not promising with only 1 partial response among 27 women [104]. A phase II clinical trial of cetuximab in recurrent endometrial cancer is still ongoing. It is hoped that other new therapies will succeed in targeting specific known molecular defects in endometrial cancer, making significant headway in the prognosis of women with metastatic disease. Meanwhile, there is a need for an expedient second-line treatment, and clinical trials should be encouraged.

Trastuzumab. HER-2 amplification or overexpression has been demonstrated and linked to prognosis in endometrial cancer as well as in many other cancer types $[105,106]$. HER-2/neu overexpression and gene amplification were found in about $20 \%-30 \%$ of serous carcinomas [91]. It is worth mentioning that in most series overexpression is more common than amplification. Trastuzumab is a monoclonal antibody to the extracellular domain of the HER-2 protein. Although HER-2 overexpression observed in serous carcinoma of the uterus provides a strong biologic rationale for the use of trastuzumab in the treatment of this malignancy, a GOG study examining the use of trastuzumab in women with HER-2 positive endometrial cancer did not report any activity [107].
4.2.3. Angiogenesis Inhibition. It has been recognised that VEGF is key to tumour angiogenesis and progression representing the cornerstone of successful antineoplastic treatments. Increased levels of VEGF in endometrial cancer have been correlated with poor outcome. Preclinical models demonstrate the effectiveness of bevacizumab in combination with chemotherapy against endometrial cancer cell lines [108, 109]. Bevacizumab, a recombinant humanized immunoglobulin monoclonal antibody to vascular endothelial growth factor (VEGF), has proved to be effective and well tolerated in a number of malignancies. A small, retrospective study reviewed 10 patients with recurrent uterine neoplasms treated with bevacizumab. Two patients responded to treatment and the disease was stabilized in three patients [110]. A GOG phase II trial of single-agent bevacizumab in metastatic endometrial cancer has recently been completed, the results of which should soon be announced (GOG 229-E). VEGFTrap is a recombinantly produced fusion protein consisting of human VEGF receptor extracellular domains fused to the Fc portion of a human immunoglobulin $\gamma$ (IgG). It functions as a decoy receptor preventing the VEGF ligand from interacting with its ligand. A GOG phase II trial of VEGF trap in metastatic endometrial cancer is still in progress (GOG 229-F) (reviewed in [80]). A phase II trial of sorafenib, a tyrosine kinase inhibitor with antiangiogenic activity, has been completed in the National Cancer Institute's phase II network (reviewed in [80]). Preliminary results were not encouraging. A phase II trial of a second antiangiogenic tyrosine kinase inhibitor, sunitinib, is underway [111]. 
4.2.4. Fibroblast Growth Factor Receptor 2 Inhibition. Fibroblast growth factor receptor 2 (FGFR2) is regulated on the basis of the balance of FGFs, heparan-sulfate proteoglycans, FGFR2 isoforms, endogenous inhibitors, and microRNAs [112]. The recent identification of activating mutations in FGFR2 in endometrial tumors has generated a new avenue for the development of targeted therapeutic agents $[113,114]$. The majority of the mutations identified are identical to germline mutations in FGFR2 and FGFR3 that cause craniosynostosis and hypochondroplasia syndromes and result in both ligand-independent and ligand-dependent receptor activation [115]. Mutations that predominantly occur in the endometrioid subtype of endometrial cancer $(16 \%)$ are mutually exclusive with KRAS mutation but occur in the presence of PTEN abrogation [116, 117]. In vitro studies have shown that endometrial cancer cell lines with activating FGFR2 mutations are selectively sensitive to a panFGFR inhibitor, PD173074 [113]. Oral administration of AZD2171 or Ki23057 inhibits in vivo proliferation of cancer cells with aberrant FGFR2 activation in rodent therapeutic models [112]. Several agents with activity against FGFRs are currently in clinical trials. Among PD173074, SU5402, and AZD2171 functioning as FGFR inhibitors, AZD2171 is the most promising anticancer drug [114]. Investigation of these agents in endometrial cancer patients with activating FGFR2 mutations is warranted [113].

\section{Claudines}

Epithelial receptors for clostridium perfringens enterotoxin (CPE), also known as claudines, may well prove to be the next target therapy for endometrial cancer, especially against aggressive disease variants. It has been shown that papillaryserous neoplasms overexpress claudines-1,-3 and -4 [118120], while clear-cell ones overexpress claudines -3 , and -4 [119]. Overexpression of claudines- 3 and -4 could in part explain the aggressive behaviour of these histologies [119, 121] suggesting their potential as useful biomarkers or targets for type specific treatment.

\section{Conclusion}

Endometrial cancer is the most common gynaecological cancer in western countries. Although radiotherapy remains the cornerstone of postoperative management, accumulating data show that adjuvant chemotherapy may display promising results after staging surgery. Unfortunately, the prognosis of patients with metastatic disease remains disappointing with only-one year survival commonly reported despite treatment efforts. Progestins remain an effective option, especially for those patients with low-grade estrogen and/or progesterone receptor positive disease. Chemotherapy comprising paclitaxel, doxorubicin, and cisplatin is beneficial for patients with advanced or metastatic disease after radical surgery and potentially for patients with early-stage disease and high-risk factors. Toxicity is a concern, in which the development of less toxic regimens such as the combination of paclitaxel with carboplatin may diminish. In women with multiple medical comorbidities, single-agent chemotherapy may be better tolerated and still yield acceptable results. A better understanding of the molecular aspects of endometrial cancer biology has allowed clinical research to develop effective and targeted antineoplastic agents (everolimus, temsirolimus, gefitinib, erlotinib, cetuximab, trastuzumab, bevacizumab, sorafenib). Although targeted therapy is in general less toxic than chemotherapy, its use may be accompanied in some instances by considerable toxicity. Continued investigation into the molecular pathways of endometrial cancer development and progression will enhance existing knowledge of this disease process promoting the discovery of novel, superior treatment options for patients.

\section{References}

[1] J. Ferlay, F. Bray, P. Pisani, and D. M. Parkin, GLOBOCAN 2002: Cancer Incidence, Mortality and Prevalence Worldwide, IARC Cancer Base no. 5, IARC Press, Lyon, France, 2004, version 2.0 .

[2] G. F. Fleming, "Systemic chemotherapy for uterine carcinoma: metastatic and adjuvant," Journal of Clinical Oncology, vol. 25, no. 20, pp. 2983-2990, 2007.

[3] R. M. Kelley and W. H. Baker, "Progestational agents in the treatment of carcinoma of the endometrium," The New England Journal of Medicine, vol. 264, pp. 216-222, 1961.

[4] S. B. Decruze and J. A. Green, "Hormone therapy in advanced and recurrent endometrial cancer: a systematic review," International Journal of Gynecological Cancer, vol. 17, no. 5, pp. 964-978, 2007.

[5] M. Markman, "Hormonal therapy of endometrial cancer," European Journal of Cancer, vol. 41, no. 5, pp. 673-675, 2005.

[6] T. Thigpen, J. Blessing, P. DiSaia, et al., "Oral medroxyprogesterone acetate in advanced or recurrent endometrial carcinoma: results of therapy and correlation with estrogen and progesterone receptor levels-The Gynecologic Oncology Group experience," in Endocrinology and Malignancy, E. Baulier, S. Iacobelli, and W. McGuire, Eds., pp. 446-454, Parthenon, Pearl River, NY, USA, 1986.

[7] J. T. Thigpen, M. F. Brady, R. D. Alvarez, et al., "Oral medroxyprogesterone acetate in the treatment of advanced or recurrent endometrial carcinoma: a dose-response study by the gynecologic oncology group," Journal of Clinical Oncology, vol. 17, no. 6, pp. 1736-1744, 1999.

[8] S. S. Lentz, M. F. Brady, F. J. Major, G. C. Reid, and J. T. Soper, "High-dose megestrol acetate in advanced or recurrent endometrial carcinoma: a Gynecologic Oncology Group study," Journal of Clinical Oncology, vol. 14, no. 2, pp. 357-361, 1996.

[9] G. M. Rendina, C. Donadio, and M. Fabri, "Tamoxifen and medroxyprogesterone therapy for advanced endometrial carcinoma," European Journal of Obstetrics Gynecology and Reproductive Biology, vol. 17, no. 4, pp. 285-291, 1984.

[10] T. Thigpen, M. F. Brady, H. D. Homesley, J. T. Soper, and J. Bell, "Tamoxifen in the treatment of advanced or recurrent endometrial carcinoma: a Gynecologic Oncology Group study," Journal of Clinical Oncology, vol. 19, no. 2, pp. 364-367, 2001.

[11] J. A. Carlson Jr., J. C. Allegra, T. G. Day Jr., and J. L. Wittliff, "Tamoxifen and endometrial carcinoma: alterations in estrogen and progesterone receptors in untreated patients and combination hormonal therapy in advanced neoplasia," 
American Journal of Obstetrics and Gynecology, vol. 149, no. 2, pp. 149-153, 1984.

[12] K. J. Pandya, B. Y. Yeap, L. M. Weiner, et al., "Megestrol and tamoxifen in patients with advanced endometrial cancer: an Eastern Cooperative Oncology Group Study (E4882)," American Journal of Clinical Oncology: Cancer Clinical Trials, vol. 24, no. 1, pp. 43-46, 2001.

[13] C. W. Whitney, V. L. Brunetto, R. J. Zaino, et al., "Phase II study of medroxyprogesterone acetate plus tamoxifen in advanced endometrial carcinoma: a Gynecologic Oncology Group study," Gynecologic Oncology, vol. 92, no. 1, pp. 4-9, 2004.

[14] D. S. McMeekin, A. Gordon, J. Fowler, et al., "A phase II trial of arzoxifene, a selective estrogen response modulator, in patients with recurrent or advanced endometrial cancer," Gynecologic Oncology, vol. 90, no. 1, pp. 64-69, 2003.

[15] C. E. Humber, J. F. Tierney, R. P. Symonds, et al., "Chemotherapy for advanced, recurrent or metastatic endometrial cancer: a systematic review of Cochrane collaboration," Annals of Oncology, vol. 18, no. 3, pp. 409-420, 2007.

[16] M. S. Carey, C. Gawlik, M. Fung-Kee-Fung, A. Chambers, and T. Oliver, "Systematic review of systemic therapy for advanced or recurrent endometrial cancer," Gynecologic Oncology, vol. 101, no. 1, pp. 158-167, 2006.

[17] J. T. Thigpen, J. A. Blessing, P. J. DiSaia, E. Yordan, L. F. Carson, and C. Evers, "A randomized comparison of doxorubicin alone versus doxorubicin plus cyclophosphamide in the management of advanced or recurrent endometrial carcinoma: a Gynecologic Oncology Group Study," Journal of Clinical Oncology, vol. 12, no. 7, pp. 1408-1414, 1994.

[18] J. T. Thigpen, M. F. Brady, H. D. Homesley, et al., "Phase III trial of doxorubicin with or without cisplatin in advanced endometrial carcinoma: a gynecologic oncology group study," Journal of Clinical Oncology, vol. 22, no. 19, pp. 3902-3908, 2004.

[19] M. S. Aapro, F. H. van Wijk, G. Bolis, et al., "Doxurubicin versus doxorubicin and cisplatin in endometrial carcinoma: definitive results of a randomised study (55872) by the EORTC Gynaecological Cancer Group," Annals of Oncology, vol. 14, no. 3, pp. 441-448, 2003.

[20] M. A. Dimopoulos, C. A. Papadimitriou, V. Georgoulias, et al., "Paclitaxel and cisplatin in advanced or recurrent carcinoma of the endometrium: long-term results of a phase II multicenter study," Gynecologic Oncology, vol. 78, no. 1, pp. 52-57, 2000.

[21] P. J. Hoskins, K. D. Swenerton, J. A. Pike, et al., "Paclitaxel and carboplatin, alone or with irradiation, in advanced or recurrent endometrial cancer: a phase II study," Journal of Clinical Oncology, vol. 19, no. 20, pp. 4048-4053, 2001.

[22] D. Pectasides, N. Xiros, G. Papaxoinis, et al., "Carboplatin and paclitaxel in advanced or metastatic endometrial cancer," Gynecologic Oncology, vol. 109, no. 2, pp. 250-254, 2008.

[23] H. D. Homesley, J. A. Blessing, J. Sorosky, G. Reid, and K. Y. Look, "Phase II trial of liposomal doxorubicin at $40 \mathrm{mg} / \mathrm{m} 2$ every 4 weeks in endometrial carcinoma: a Gynecologic Oncology Group Study," Gynecologic Oncology, vol. 98, no. 2, pp. 294-298, 2005.

[24] A. du Bois, J. Pfisterer, N. Burchardi, et al., "Combination therapy with pegylated liposomal doxorubicin and carboplatin in gynecologic malignancies: a prospective phase II study of the Arbeitsgemeinschaft Gynaekologische Onkologie Studiengruppe Ovarialkarzinom (AGO-OVAR) and Kommission Uterus (AGO-K-Ut)," Gynecologic Oncology, vol. 107, no. 3, pp. 518-525, 2007.
[25] S. Pignata, G. Scambia, C. Pisano, et al., "A multicentre phase II study of carboplatin plus pegylated liposomal doxorubicin as first-line chemotherapy for patients with advanced or recurrent endometrial carcinoma: the END-1 study of the MITO (Multicentre Italian Trials in Ovarian Cancer and Gynecologic Malignancies) group," British Journal of Cancer, vol. 96, no. 11, pp. 1639-1643, 2007.

[26] A. Lissoni, A. Gabriele, G. Gorga, et al., "Cisplatin-, epirubicin- and paclitaxel-containing chemotherapy in uterine adenocarcinoma," Annals of Oncology, vol. 8, no. 10, pp. 969-972, 1997.

[27] C. A. Papadimitriou, D. Bafaloukos, G. Bozas, et al., "Paclitaxel, epirubicin, and carboplatin in advanced or recurrent endometrial carcinoma: a Hellenic Co-operative Oncology Group (HeCOG) study," Gynecologic Oncology, vol. 110, no. 1, pp. 87-92, 2008.

[28] C. A. Papadimitriou, G. Fountzilas, D. Bafaloukos, et al., "Paclitaxel, topotecan, and carboplatin in metastatic endometrial cancinoma: a Hellenic Co-operative Oncology Group (HeCOG) study," Gynecologic Oncology, vol. 111, no. 1, pp. 27-34, 2008.

[29] G. F. Fleming, V. L. Brunetto, D. Cella, et al., "Phase III trial of doxorubicin plus cisplatin with or without paclitaxel plus filgrastim in advanced endometrial carcinoma: a gynecologic oncology group study," Journal of Clinical Oncology, vol. 22, no. 11, pp. 2159-2166, 2004.

[30] M. S. Piver, S. B. Lele, B. Patsner, and L. J. Emrich, "Melphalan, 5-fluorouracil, and medroxyprogesterone acetate in metastatic endometrial carcinoma," Obstetrics and Gynecology, vol. 67, no. 2, pp. 261-264, 1986.

[31] T. L. Cornelison, T. R. Baker, M. S. Piver, and D. L. Driscoll, "Cisplatin, adriamycin, etoposide, megestrol acetate versus melphalan, 5- fluorouracil, medroxyprogesterone acetate in the treatment of endometrial carcinoma," Gynecologic Oncology, vol. 59, no. 2, pp. 243-248, 1995.

[32] M. F. Fung, G. V. Krepart, R. J. Lotocki, and M. Heywood, "Treatment of recurrent and metastatic adenocarcinoma of the endometrium with cisplatin, doxorubicin, cyclophosphamide, and medroxyprogesterone acetate," Obstetrics and Gynecology, vol. 78, no. 6, pp. 1033-1038, 1991.

[33] D. Bafaloukos, G. Aravantinos, G. Samonis, et al., "Carboplatin, methotrexate and 5-fluorouracil in combination with medroxyprogesterone acetate (JMF-M) in the treatment of advanced or recurrent endometrial carcinoma: a Hellenic Cooperative Oncology Group study," Oncology, vol. 56, no. 3, pp. 198-201, 1999.

[34] J. Ayoub, P. Audet-Lapointe, Y. Methot, et al., "Efficacy of sequential cyclical hormonal therapy in endometrial cancer and its correlation with steroid hormone receptor status," Gynecologic Oncology, vol. 31, no. 2, pp. 327-337, 1988.

[35] G. F. Fleming, V. L. Filiaci, R. C. Bentley, et al., "Phase III randomized trial of doxorubicin + cisplatin versus doxorubicin + 24-h paclitaxel + filgrastim in endometrial carcinoma: a Gynecologic Oncology Group study," Annals of Oncology, vol. 15, no. 8, pp. 1173-1178, 2004.

[36] G. Mountzios, A. Bamias, Z. Voulgaris, et al., "Prognostic factors in patients treated with taxane-based chemotherapy for recurrent or metastatic endometrial cancer: proposal for a new prognostic model," Gynecologic Oncology, vol. 108, no. 1, pp. 130-135, 2008.

[37] H. D. Homesley, N. P. Meltzer, L. Nieves, L. Vaccarello, G. S. Lowendowski, and A. A. Elbendary, "A phase II trial of weekly 1-hour paclitaxel as second-line therapy for endometrial and 
cervical cancer," International Journal of Clinical Oncology, vol. 13, no. 1, pp. 62-65, 2008.

[38] S. Lincoln, J. A. Blessing, R. B. Lee, and T. F. Rocereto, "Activity of paclitaxel as second-line chemotherapy in endometrial carcinoma: a Gynecologic Oncology Group study," Gynecologic Oncology, vol. 88, no. 3, pp. 277-281, 2003.

[39] A. Lissoni, G. Zanetta, G. Losa, A. Gabriele, G. Parma, and C. Mangioni, "Phase II study of paclitaxel as salvage treatment in advanced endometrial cancer," Annals of Oncology, vol. 7, no. 8, pp. 861-863, 1996.

[40] M. Mazgani, N. Le, and P. J. Hoskins, "Reuse of carboplatin and paclitaxel in patients with relapsed endometrial cancerthe British Columbia Cancer Agency experience," Gynecologic Oncology, vol. 111, no. 3, pp. 474-477, 2008.

[41] C. L. Creutzberg, W. L. J. van Putten, P. C. M. Koper, et al., "Surgery and postoperative radiotherapy versus surgery alone for patients with stage-1 endometrial carcinoma: multicentre randomised trial," The Lancet, vol. 355, no. 9213, pp. 1404-1411, 2000.

[42] J. D. Sears, K. M. Greven, H. M. Hoen, and M. E. Randall, "Prognostic factors and treatment outcome for patients with locally recurrent endometrial cancer," Cancer, vol. 74, no. 4, pp. 1303-1308, 1994.

[43] H. M. Keys, J. A. Roberts, V. L. Brunetto, et al., "A phase III trial of surgery with or without adjunctive external pelvic radiation therapy in intermediate risk endometrial adenocarcinoma: a Gynecologic Oncology Group study," Gynecologic Oncology, vol. 92, no. 3, pp. 744-751, 2004.

[44] W. Creasman, F. Odicino, P. Maisonneuve, et al., "Carcinoma of the corpus uteri," International Journal of Gynecology and Obstetrics, vol. 95, supplement 1, pp. S105-S143, 2006.

[45] W. T. Creasman, M. F. Kohler, F. Odicino, P. Maisonneuve, and P. Boyle, "Prognosis of papillary serous, clear cell, and grade 3 stage I carcinoma of the endometrium," Gynecologic Oncology, vol. 95, no. 3, pp. 593-596, 2004.

[46] C. L. Creutzberg, W. L. J. van Putten, C. C. WarlainRodenhtiis, et al., "Outcome of high-risk stage IC, grade 3, compared with stage I endometrial carcinoma patients: the postoperative radiation therapy in endometrial carcinoma trial," Journal of Clinical Oncology, vol. 22, no. 7, pp. 12341241, 2004.

[47] G. von Minckwitz, S. Loibl, K. Brunnert, et al., "Adjuvant endocrine treatment with medroxyprogesterone acetate or tamoxifen in stage I and II endometrial cancer-a multicentre, open, controlled, prospectively randomised trial," European Journal of Cancer, vol. 38, no. 17, pp. 2265-2271, 2002.

[48] P. L. Martin-Hirsch, G. Jarvis, H. Kitchener, and R. Lilford, "Progestagens for endometrial cancer," Cochrane Database of Systematic Reviews, no. 2, Article ID CD001040, 2000.

[49] M. E. Randall, V. L. Filiaci, H. Muss, et al., "Randomized phase III trial of whole-abdominal irradiation versus doxorubicin and cisplatin chemotherapy in advanced endometrial carcinoma: a Gynecologic Oncology Group study," Journal of Clinical Oncology, vol. 24, no. 1, pp. 36-44, 2006.

[50] R. Maggi, A. Lissoni, F. Spina, et al., "Adjuvant chemotherapy vs radiotherapy in high-risk endometrial carcinoma: results of a randomised trial," British Journal of Cancer, vol. 95, no. 3, pp. 266-271, 2006.

[51] T. Kuoppala, J. Maenpaa, E. Tomas, et al., "Surgically staged high-risk endometrial cancer: randomized study of adjuvant radiotherapy alone vs. sequential chemo-radiotherapy," Gynecologic Oncology, vol. 110, no. 2, pp. 190-195, 2008.
[52] N. Susumu, S. Sagae, Y. Udagawa, et al., "Randomized phase III trial of pelvic radiotherapy versus cisplatin-based combined chemotherapy in patients with intermediateand high-risk endometrial cancer: a Japanese Gynecologic Oncology Group study," Gynecologic Oncology, vol. 108, no. 1, pp. 226-233, 2008.

[53] T. Hogberg, P. Rosenberg, G. Kristensen, et al., "A randomized phase-III study on adjuvant treatment with radiation (RT) $\{+/-\}$ chemotherapy (CT) in early-stage highrisk endometrial cancer (NSGO-EC-9501/EORTC 55991)," Journal of Clinical Oncology, vol. 25, p. 5503, 2007.

[54] K. Greven, K. Winter, K. Underhill, J. Fontenesci, J. Cooper, and T. Burke, "Final analysis of RTOG 9708: adjuvant postoperative irradiation combined with cisplatin/paclitaxel chemotherapy following surgery for patients with high-risk endometrial cancer," Gynecologic Oncology, vol. 103, no. 1, pp. 155-159, 2006.

[55] M. A. Sovak, M. L. Hensley, J. Dupont, et al., "Paclitaxel and carboplatin in the adjuvant treatment of patients with high-risk stage III and IV endometrial cancer: a retrospective study," Gynecologic Oncology, vol. 103, no. 2, pp. 451-457, 2006.

[56] H. D. Homesley, V. Filiaci, S. K. Gibbons, et al., "A randomized phase III trial in advanced endometrial carcinoma of surgery and volume directed radiation followed by cisplatin and doxorubicin with or without paclitaxel: a Gynecologic Oncology Group study," Gynecologic Oncology, vol. 112, no. 3, pp. 543-552, 2009.

[57] C. S. Dietrich III, S. C. Modesitt, P. D. Depriest, et al., "The efficacy of adjuvant platinum-based chemotherapy in Stage I uterine papillary serous carcinoma (UPSC)," Gynecologic Oncology, vol. 99, no. 3, pp. 557-563, 2005.

[58] C. A. Hamilton, M. K. Cheung, K. Osann, et al., "The effect of adjuvant chemotherapy versus whole abdominopelvic radiation on the survival of patients with advanced stage uterine papillary serous carcinoma," Gynecologic Oncology, vol. 103, no. 2, pp. 679-683, 2006.

[59] M. G. Kelly, D. M. O’Malley, P. Hui, et al., "Improved survival in surgical stage I patients with uterine papillary serous carcinoma (UPSC) treated with adjuvant platinum-based chemotherapy," Gynecologic Oncology, vol. 98, no. 3, pp. 353359, 2005.

[60] J. S. H. Low, E. H. Wong, H. S. K. Tan, et al., "Adjuvant sequential chemotherapy and radiotherapy in uterine papillary serous carcinoma," Gynecologic Oncology, vol. 97, no. 1, pp. 171-177, 2005.

[61] K. M. Zanotti, J. L. Belinson, A. W. Kennedy, K. D. Webster, and M. Markman, "The use of paclitaxel and platinumbased chemotherapy in uterine papillary serous carcinoma," Gynecologic Oncology, vol. 74, no. 2, pp. 272-277, 1999.

[62] A. L. Fields, M. H. Einstein, A. P. Novetsky, J. Gebb, and G. L. Goldberg, "Pilot phase II trial of radiation "sandwiched" between combination paclitaxel/platinum chemotherapy in patients with uterine papillary serous carcinoma (UPSC)," Gynecologic Oncology, vol. 108, no. 1, pp. 201-206, 2008.

[63] Y. Aoki, M. Watanabe, T. Amikura, et al., "Adjuvant chemotherapy as treatment of high-risk stage I and II endometrial cancer," Gynecologic Oncology, vol. 94, no. 2, pp. 333-339, 2004.

[64] T. Pustilnik and T. W. Burke, "Adjuvant chemotherapy for high-risk endometrial cancer," Seminars in Radiation Oncology, vol. 10, no. 1, pp. 23-28, 2000.

[65] T. W. Burke, D. M. Gershenson, M. Morris, et al., "Postoperative adjuvant cisplatin, doxorubicin, and cyclophosphamide 
(PAC) chemotherapy in women with high-risk endometrial carcinoma," Gynecologic Oncology, vol. 55, no. 1, pp. 47-50, 1994.

[66] C. A. Stringer, D. M. Gershenson, T. W. Burke, C. L. Edwards, A. N. Gordon, and J. T. Wharton, "Adjuvant chemotherapy with cisplatin, doxorubicin, and cyclophosphamide (PAC) for early-stage high-risk endometrial cancer: a preliminary analysis," Gynecologic Oncology, vol. 38, no. 3, pp. 305-308, 1990.

[67] G. T. Bozas, A. Bamias, E. Kastritis, et al., "Adjuvant chemotherapy with paclitaxel and carboplatin in nonendometrioid carcinoma of the uterus," European Journal of Gynaecological Oncology, vol. 26, no. 6, pp. 627-631, 2005.

[68] J. H. Edmonson, J. E. Krook, and J. F. Hilton, "Randomized Phase II studies of cisplatin and a combination of cyclophosphamide-doxorubicin-cisplatin (CAP) in patients with progestin-refractory advanced endometrial carcinoma," Gynecologic Oncology, vol. 28, no. 1, pp. 20-24, 1987.

[69] S. Kounelis, N. Kapranos, E. Kouri, D. Coppola, H. Papadaki, and M. W. Jones, "Immunohistochemical profile of endometrial adenocarcinoma: a study of 61 cases and review of the literature," Modern Pathology, vol. 13, no. 4, pp. 379-388, 2000.

[70] S. F. Lax, E. S. Pizer, B. M. Ronnett, and R. J. Kurman, "Clear cell carcinoma of the endometrium is characterized by a distinctive profile of p53, Ki-67, estrogen, and progesterone receptor expression," Human Pathology, vol. 29, no. 6, pp. 551-558, 1998.

[71] F. Darvishian, A. J. Hummer, H. T. Thaler, et al., "Serous endometrial cancers that mimic endometrioid adenocarcinomas: a clinicopathologic and immunohistochemical study of a group of problematic cases," American Journal of Surgical Pathology, vol. 28, no. 12, pp. 1568-1578, 2004.

[72] G. E. Konecny, L. Santos, B. Winterhoff, et al., "HER2 gene amplification and EGFR expression in a large cohort of surgically staged patients with nonendometrioid (type II) endometrial cancer," British Journal of Cancer, vol. 100, no. 1, pp. 89-95, 2009.

[73] J. V. Bokhman, "Two pathogenetic types of endometrial carcinoma," Gynecologic Oncology, vol. 15, no. 1, pp. 10-17, 1983.

[74] J. Prat, "Prognostic parameters of endometrial carcinoma," Human Pathology, vol. 35, no. 6, pp. 649-662, 2004.

[75] J. L. Hecht and G. L. Mutter, "Molecular and pathologic aspects of endometrial carcinogenesis," Journal of Clinical Oncology, vol. 24, no. 29, pp. 4783-4791, 2006.

[76] N. Bansal, V. Yendluri, and R. M. Wenham, "The molecular biology of endometrial cancers and the implications for pathogenesis, classification, and targeted therapies," Cancer Control, vol. 16, no. 1, pp. 8-13, 2009.

[77] L. K. Mell, J. J. Meyer, M. Tretiakova, et al., "Prognostic significance of E-cadherin protein expression in pathological stage I-III endometrial cancer," Clinical Cancer Research, vol. 10, no. 16, pp. 5546-5553, 2004.

[78] G. Moreno-Bueno, D. Hardisson, D. Sarrio, et al., "Abnormalities of E- and P-cadherin and catenin $(\beta-, \gamma$-catenin, and p120ctn) expression in endometrial cancer and endometrial atypical hyperplasia," Journal of Pathology, vol. 199, no. 4, pp. 471-478, 2003.

[79] L. Jia, Y. Liu, X. Yi, et al., "Endometrial glandular dysplasia with frequent p53 gene mutation: a genetic evidence supporting its precancer nature for endometrial serous carcinoma," Clinical Cancer Research, vol. 14, no. 8, pp. 22632269, 2008.
[80] S. M. Temkin and G. Fleming, "Current treatment of metastatic endometrial cancer," Cancer Control, vol. 16, no. 1, pp. 38-45, 2009.

[81] G. L. Mutter, M.-C. Lin, J. T. Fitzgerald, et al., "Altered PTEN expression as a diagnostic marker for the earliest endometrial precancers," Journal of the National Cancer Institute, vol. 92, no. 11, pp. 924-930, 2000.

[82] M. C. Boruban, K. Altundag, G. S. Kilic, and J. Blankstein, "From endometrial hyperplasia to endometrial cancer: insight into the biology and possible medical preventive measures," European Journal of Cancer Prevention, vol. 17, no. 2, pp. 133-138, 2008.

[83] K. Oda, D. Stokoe, Y. Taketani, and F. McCormick, "High frequency of coexistent mutations of PIK3CA and PTEN genes in endometrial carcinoma," Cancer Research, vol. 65, no. 23, pp. 10669-10673, 2005.

[84] K. Kurose, X.-P. Zhou, T. Araki, S. A. Cannistra, E. R. Maher, and C. Eng, "Frequent loss of PTEN expression is linked to elevated phosphorylated Akt levels, but not associated with p27 and cyclin D1 expression, in primary epithelial ovarian carcinomas," American Journal of Pathology, vol. 158, no. 6, pp. 2097-2106, 2001.

[85] J. B. Basil, P. J. Goodfellow, J. S. Rader, D. G. Mutch, and T. J. Herzog, "Clinical significance of microsatellite instability in endometrial carcinoma," Cancer, vol. 89, no. 8, pp. 17581764, 2000.

[86] S. F. Lax, B. Kendall, H. Tashiro, R. J. C. Slebos, and L. H. Ellenson, "The frequency of p53, K-ras mutations, and microsatellite instability differs in uterine endometrioid and serous carcinoma: evidence of distinct molecular genetic pathways," Cancer, vol. 88, no. 4, pp. 814-824, 2000.

[87] M. Saegusa, M. Hashimura, T. Yoshida, and I. Okayasu, “ $\beta$ catenin mutations and aberrant nuclear expression during endometrial tumorigenesis," British Journal of Cancer, vol. 84, no. 2, pp. 209-217, 2001.

[88] C. Bilbao, G. Rodríguez, R. Ramírez, et al., "The relationship between microsatellite instability and PTEN gene mutations in endometrial cancer," International Journal of Cancer, vol. 119, no. 3, pp. 563-570, 2006.

[89] A. Doll, M. Abal, M. Rigau, et al., "Novel molecular profiles of endometrial cancer-new light through old windows," Journal of Steroid Biochemistry and Molecular Biology, vol. 108, no. 3-5, pp. 221-229, 2008.

[90] G. Moreno-Bueno, D. Hardisson, C. Sánchez, et al., "Abnormalities of the APC/ $\beta$-catenin pathway in endometrial cancer," Oncogene, vol. 21, no. 52, pp. 7981-7990, 2002.

[91] S. C. Hye, W. Hu, and J. J. Kavanagh, "Targeted therapies in gynecologic cancers," Current Cancer Drug Targets, vol. 6, no. 4, pp. 333-363, 2006.

[92] A. M. Oza, L. Elit, J. Biagi, et al., "Molecular correlates associated with a phase II study of temsirolimus (CCI-779) in patients with metastatic or recurrent endometrial cancerNCIC IND 160," Journal of Clinical Oncology, vol. 24, no. 18S, p. 3003, 2006, ASCO Annual Meeting Proceedings (PostMeeting Edition).

[93] B. M. Slomovitz, T. Murke, K. H. Lu, et al., "Loss of PTEN expression associated with response to RAD001 (mTor inhibitor) in patients with recurrent endometrial cancer: translational evaluation from a phase II study," in Proceedings of the 38th Annual Meeting Society of Gynecologic Oncologists, vol. 104, p. 70, San Diego, Calif, USA, March 2007.

[94] N. Colombo, S. McMeekin, P. Schwartz, et al., "A phase II trial of the mTor inhibitor AP23573 as a single agent in advanced endometrial cancer," Journal of Clinical Oncology, vol. 25, 
no. 18S, p. 5516, 2007, ASCO Annual Meeting Proceedings. Part I.

[95] B. M. Slomovitz, K. H. Lu, T. Johnston, et al., "A phase II study of oral mammalian target of rapamycin (mTOR) inhibitor, RAD001 (everolimus), in patients with recurrent endometrial carcinoma (EC)," Journal of Clinical Oncology, vol. 26, p. 5502, 2008, meeting abstracts.

[96] A. M. Oza, L. Elit, D. Provencher, et al., "A phase II study of temsirolimus (CCI-779) in patients with metastatic and/or locally advanced recurrent endometrial cancer previously treated with chemotherapy: NCIC CTG IND 160b," Journal of Clinical Oncology, vol. 26, 2008, ASCO Annual Meeting Proceedings (Post-Meeting Edition).

[97] V. L. Bae-Jump, C. Zhou, J. F. Boggess, et al., "The effect of rapamycin on progesterone receptor and estrogen receptor expression in endometrial cancer cells," in Proceedings of the 39th Annual Meeting Society of Gynecologic Oncologists, vol. 108, p. 168, Tampa, Fla, USA, March 2009.

[98] KK. Leslie, L. Laidler, L. Albitar, et al., "Tyrosine kinase inhibitors in endometrial cancer," International Journal of Gynecological Cancer, vol. 15, no. 2, pp. 409-411, 2005.

[99] H. Niikura, H. Sasano, G. Matsunaga, et al., "Prognostic value of epidermal growth factor receptor expression in endometrioid endometrial carcinoma," Human Pathology, vol. 26, no. 8, pp. 892-896, 1995.

[100] P. Athanassiadou, E. Petrakakou, A. Liossi, et al., "Prognostic significance of p53, bcl-2 and EGFR in carcinoma of the endometrium," Acta Cytologica, vol. 43, no. 6, pp. 1039-1044, 1999.

[101] E. S. Gershtein, L. B. Bocharova, V. D. Ermilova, K. P. Laktionov, and Kushlinskiî, "Epidermal growth factor receptors and their ligands in endometrial carcinoma: correlation with clinico-morphologic factors and steroid receptors," Voprosy Onkologii, vol. 46, no. 2, pp. 180-186, 2000.

[102] M. A. Khalifa, R. S. Mannel, S. D. Haraway, J. Walker, and K.W. Min, "Expression of EGFR, HER-2/neu, P53, and PCNA in endometrioid, serous papillary, and clear cell endometrial adenocarcinomas," Gynecologic Oncology, vol. 53, no. 1, pp. 84-92, 1994.

[103] N. Nagai, T. Oshita, T. Fujii, H. Kioka, Y. Katsube, and K. Ohama, "Prospective analysis of DNA ploidy, proliferative index and epidermal growth factor receptor as prognostic factors for pretreated uterine cancer," Oncology Reports, vol. 7, no. 3, pp. 551-559, 2000.

[104] A. M. Oza, E. A. Eisenhauer, L. Elit, et al., "Phase II study of erlotinib in recurrent or metastatic endometrial cancer: NCIC IND-148," Journal of Clinical Oncology, vol. 26, no. 26, pp. 4319-4325, 2008.

[105] G. E. Konecny, L. Santos, B. Winterhoff, et al., "HER2 gene amplification and EGFR expression in a large cohort of surgically staged patients with nonendometrioid (type II) endometrial cancer," British Journal of Cancer, vol. 100, no. 1, pp. 89-95, 2009.

[106] T. A. Grushko, V. L. Filiaci, A. J. Mundt, K. Ridderstråle, O. I. Olopade, and G. F. Fleming, "An exploratory analysis of HER-2 amplification and overexpression in advanced endometrial carcinoma: a gynecologic oncology group study," Gynecologic Oncology, vol. 108, no. 1, pp. 3-9, 2008.

[107] G. Fleming, M. Sill, J. Thigpen, et al., "Phase II evaluation of trastuzumab in patients with advanced or recurrent endometrial carcinoma: a report on GOG 181B," in Proceedings of the 39th Annual Meeting American Society for Clinical Oncology, vol. 22, p. 453, Chicago, Ill, USA, May-June 2003.
[108] A. A. Kamat, W. M. Merritt, D. Coffey, et al., "Clinical and biological significance of vascular endothelial growth factor in endometrial cancer," Clinical Cancer Research, vol. 13, no. 24, pp. 7487-7495, 2007.

[109] D. S. McMeekin, M. W. Sill, D. Benbrook, et al., "A phase II trial of thalidomide in patients with refractory endometrial cancer and correlation with angiogenesis biomarkers: a Gynecologic Oncology Group study," Gynecologic Oncology, vol. 105, no. 2, pp. 508-516, 2007.

[110] J. D. Wright, M. A. Powell, J. S. Rader, D. G. Mutch, and R. K. Gibb, "Bevacizumab therapy in patients with recurrent uterine neoplasms," Anticancer Research, vol. 27, no. 5, pp. 3525-3528, 2007.

[111] H. S. Nimeiri, A. M. Oza, R. J. Morgan, et al., "Sorafenib (SOR) in patients (pts) with advanced/recurrent uterine carcinoma (UCA) or carcinosarcoma(CS): a phase II trial of the University of Chicago, PMH, and California Phase II Consortia," Journal of Clinical Oncology, vol. 26, 2008, ASCO Annual Meeting Proceedings (Post-Meeting Edition).

[112] S. A. Byron and P. M. Pollock, "FGFR2 as a molecular target in endometrial cancer," Future Oncology, vol. 5, no. 1, pp. 27$32,2009$.

[113] M. Katoh, "FGFR2 abnormalities underlie a spectrum of bone, skin, and cancer pathologies," Journal of Investigative Dermatology, vol. 129, no. 8, pp. 1861-1867, 2009.

[114] M. Katoh, "Cancer genomics and genetics of FGFR2 (Review)," International Journal of Oncology, vol. 33, no. 2, pp. 233-237, 2008.

[115] P. M. Pollock, M. G. Gartside, L. C. Dejeza, et al., "Frequent activating FGFR2 mutations in endometrial carcinomas parallel germline mutations associated with craniosynostosis and skeletal dysplasia syndromes," Oncogene, vol. 26, no. 50, pp. 7158-7162, 2007.

[116] S. A. Byron, M. G. Gartside, C. L. Wellens, et al., "Inhibition of activated fibroblast growth factor receptor 2 in endometrial cancer cells induces cell death despite PTEN abrogation," Cancer Research, vol. 68, no. 17, pp. 6902-6907, 2008.

[117] S. A. Byron, M. G. Gartside, C. J. Wellens, et al., "Correction: inhibition of activated FGFR2 in endometrial cancer," Cancer Research, vol. 68, no. 23, article 10005, 2008.

[118] G. Sobel, J. Nemeth, A. Kiss, et al., "Claudin 1 differentiates endometrioid and serous papillary endometrial adenocarcinoma," Gynecologic Oncology, vol. 103, no. 2, pp. 591-598, 2006.

[119] G. E. Konecny, R. Agarwal, G. A. Keeney, et al., "Claudin-3 and claudin-4 expression in serous papillary, clear-cell, and endometrioid endometrial cancer," Gynecologic Oncology, vol. 109, no. 2, pp. 263-269, 2008.

[120] X. Y. Pan, B. Wang, Y. C. Che, Z. P. Weng, H. Y. Dai, and W. Peng, "Expression of claudin-3 and claudin-4 in normal, hyperplastic, and malignant endometrial tissue," International Journal of Gynecological Cancer, vol. 17, no. 1, pp. 233-241, 2007.

[121] A. D. Santin, S. Bellone, M. Marizzoni, et al., "Overexpression of claudin-3 and claudin-4 receptors in uterine serous papillary carcinoma: novel targets for a type-specific therapy using Clostridium perfringens enterotoxin (CPE)," Cancer, vol. 109, no. 7, pp. 1312-1322, 2007. 


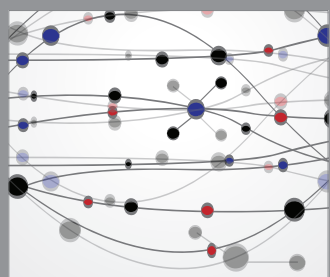

The Scientific World Journal
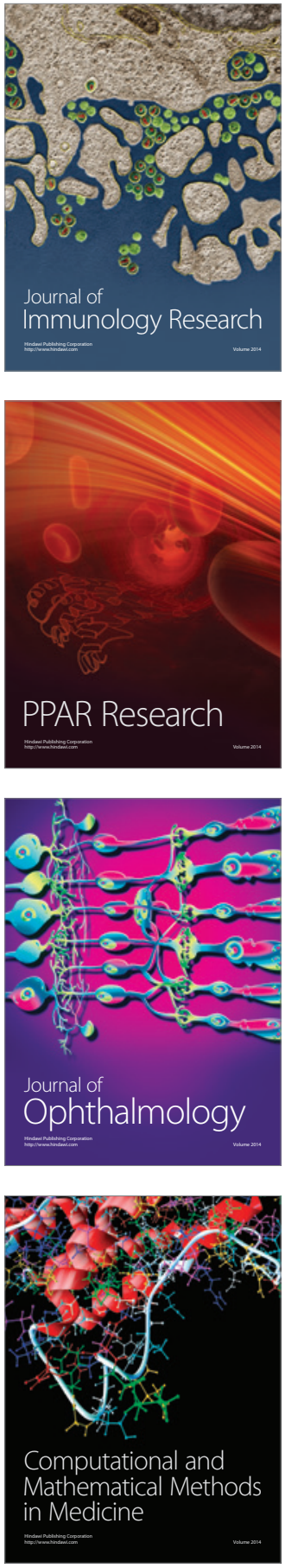

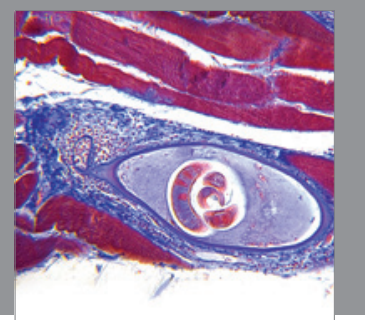

Gastroenterology

Research and Practice
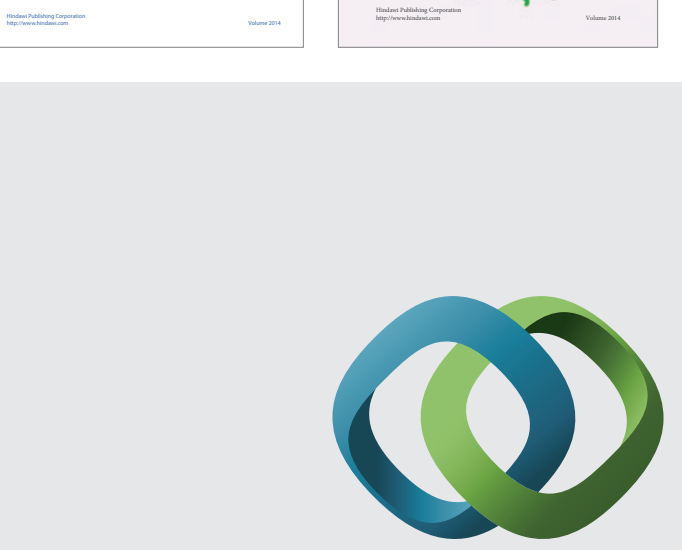

\section{Hindawi}

Submit your manuscripts at

http://www.hindawi.com
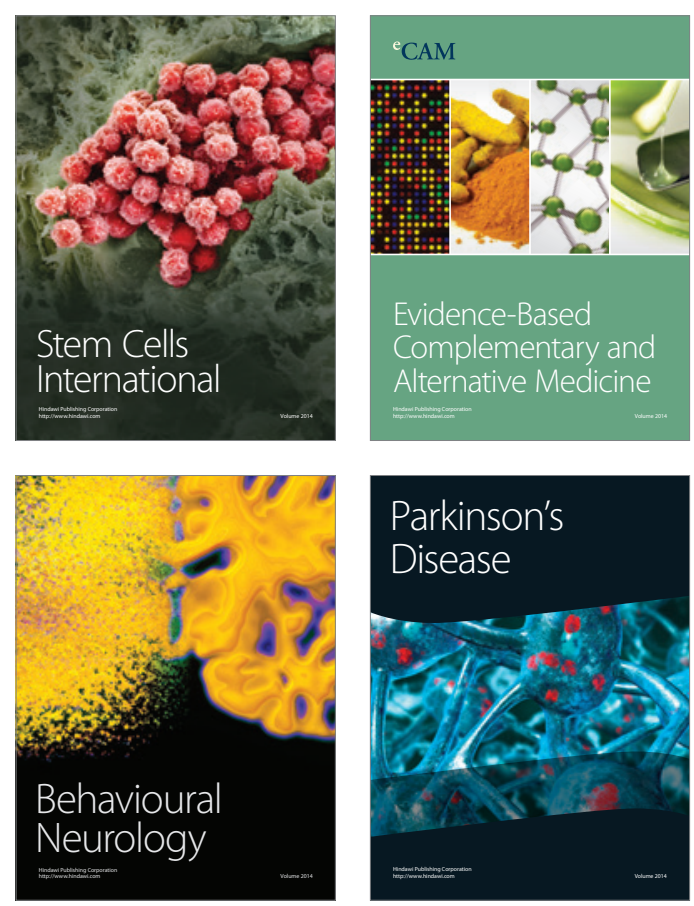

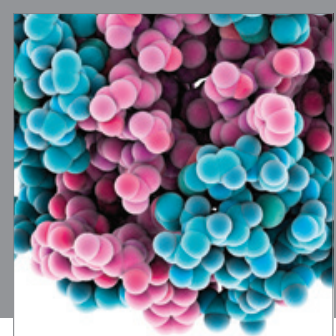

Journal of
Diabetes Research

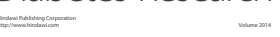

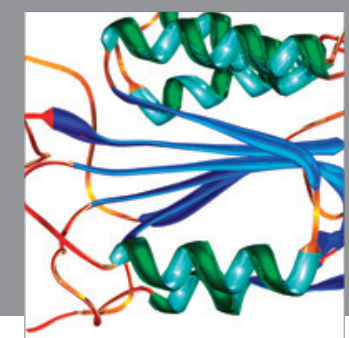

Disease Markers
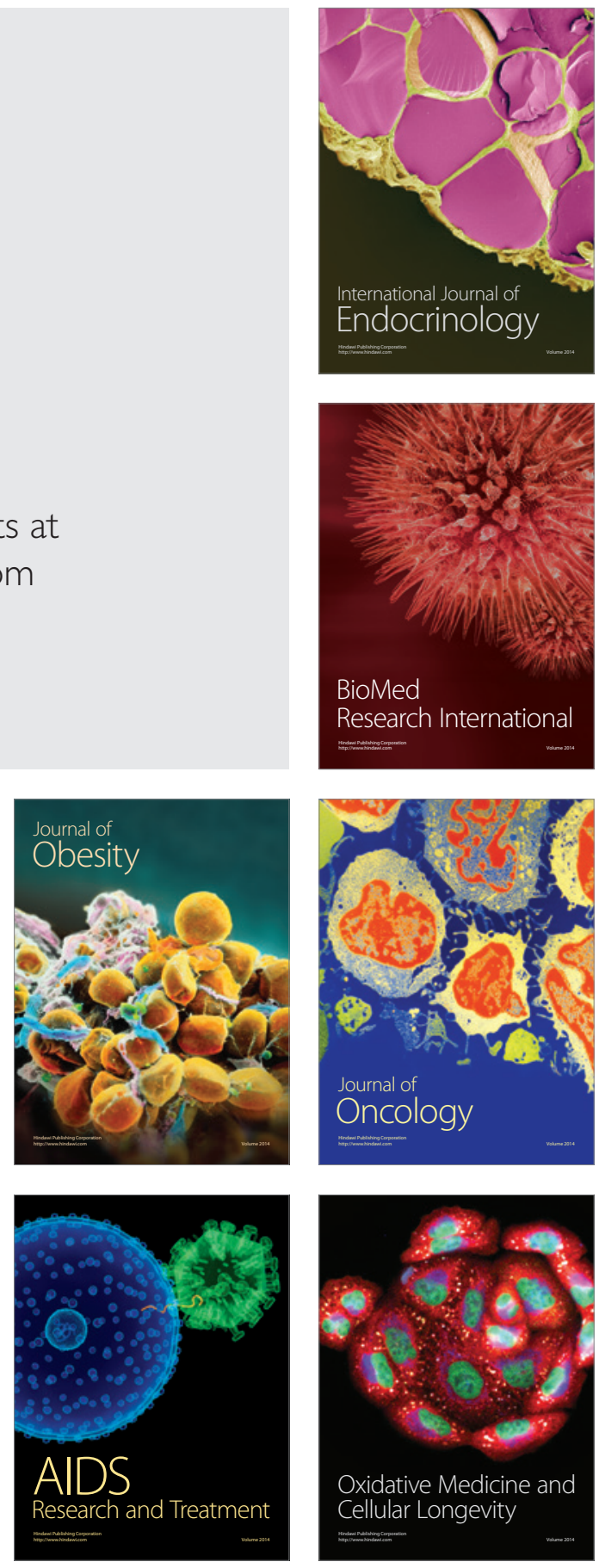